volunteers in suicide prevention, patients functioning as therapists in drug dependence programmes like Alcoholics Anonymous, and family members becoming therapists to other family members. The key characteristic of this sort of 'service' is the limited role individuals take on in one specific situation, in which they call on their own personal experiences. The strength of these personnel is in their focused expertise and their acceptance by help seekers.

o To involve staff in other sectors. As part of the 'deprofessionalisation' of mental health services, personnel working in different sectors (e.g. education or police) have frequently been used. Here, the health worker, preschool teacher, schoolteacher, police officer and so on add on a component of mental health to their traditional work activities.
Hongoro, C. \& McPake, B. (2004) How to bridge the gap in human resources for health. Lancet, 364, 1451-1456.

Jenkins, C. (2004) Ethical international recruitment. International Psychiatry, issue 6, 18-19.

N detei, D., Karim, S. \& Mubbashar, M. (2004) Recruitment of consultant psychiatrists from low- and middle-income countries. International Psychiatry, issue 6, 15-18.

Srinivasa Murthy, R. (2000) Community resources for mental health care in India. Epidemiologia e Psychiatria Sociale, 9, 89- 92.

Srinivasa Murthy, R. \& Wig, N. N. (1983) The WHO collaborative study on Strategies for Extending Mental Health Care, IV: a training approach to enhancing the availability of mental health manpower in a developing country. American Journal of Psychiatry, 140, 1486-1490.

World Health Organization (2001a) World Health Report 2001. M ental Health: New Understanding, N ew Hope. Geneva: WHO.

World Health O rganization (2001b). Atlas. Country Profiles on Mental Health Resources 2001. Geneva: WHO

World Health Organization (2003) The World Health Report 2003. Geneva: WHO.
As part of the

'deprofessionalisation'

of mental health

services ... the

health worker,

preschool teacher,

schoolteacher,

police officer and

so on add on a

component of

mental health to

their traditional

work activities.

\title{
The International Fellowship Programme: some personal thoughts
}

\author{
Gareth J. Holsgrove
}

Medical Education Adviser, Royal College of Psychiatrists, London, UK, email: gholsgrove@rcpsych.ac.uk

Trente he International Fellowship Programme (IFP) was launched in 2003 under the name of the International Fellowship Scheme, its title being changed in 2004 because it was causing confusion to US doctors, who interpreted the word 'scheme' as having Machiavellian implications.

The purpose of the IFP is to recruit senior doctors from overseas on short-term contracts to fill consultant vacancies in the $\mathrm{N}$ ational $\mathrm{H}$ ealth Service (N HS). From its very inception, though, it has been severely criticised, for a variety of reasons. Since the number of psychiatrists recruited under the Programme exceeds that of every other specialty put together, the Royal College of Psychiatrists has unsurprisingly become strongly associated with much of the criticism. Indeed, a great deal of it has come from within the College's own membership, and by far its most common basis has been the ethics of recruiting highly qualified doctors from low- and middleincome countries.

Most of the issues have already been discussed in some detail in various publications. For example, Patel (2003) asks whether the N HS could justify schemes to recruit staff from poor countries, and points out that:

$O$ the developing world has fewer doctors per head of population than developed countries o recruiting from these countries damages their fragile health systems

o the cost of their training has been borne by the poor country, yet the rich country reaps the benefit.

Mellor (2003), in a commentary on Patel's article, maintains that recruitment is ethical and that most of the staff being recruited are from Europe, with others from the United States and Australia. While she undoubtedly has access to comprehensive recruitment data, this statement certainly does not apply to psychiatrists recruited under the IFP, the great majority of whom come from India. As far as I can recall, only one psychiatrist has been recruited on this programme from Australia, and none from $\mathrm{N}$ orth America.

$\mathrm{N}$ detei et al (2004) present a strong and persuasive case in their paper, to which Jenkins (2004) responded. Shortly afterwards, Khan (2004) wrote on 'The N HS International Fellowship Scheme in psychiatry: robbing the poor to pay the rich?', to which Goldberg (2004) replied. The essence of the debate is that Patel, $\mathrm{N}$ detei et al and Khan maintain that the IFP is unethical because it is recruiting doctors from countries that can least afford to lose them, whereas Mellor, Jenkins and Goldberg counter by saying that the UK leads the way in developing and implementing recruitment policies of the kind called for by
Disclaimer: These are the writer's personal views and do not necessarily reflect the official College position on the International Fellowship Programme. 
the World Health $\mathrm{O}$ rganization. However, the debate appears to have a long way to run, although there does seem to be a risk that it will generate more heat than light.

\section{The International Fellowship Programme}

The IFP has two declared aims. It is primarily to recruit overseas doctors to work in consultant posts in the NHS, in a number of identified shortage areas. Its secondary aim is to offer overseas doctors the opportunity to work in the unique healthcare system that the N HS represents, which will include the opportunity to learn new skills and to experience life in the UK. This, though, must be seen as a minor aim of the programme. Patel (2003) says it is a marketing pitch. The N HS is trying to fill jobs in which there is a shortage of staff, rather than to realise a desire to broaden the professional experience of overseas doctors. As N detei et al (2004) point out, there are better ways of learning new skills, which can be tailored to the service context of their own countries. They also point out that experience has shown that health personnel who move to a rich country for more than a few months are likely to stay there, particularly if they bring their families with them. Patel (2003) reports that experience with other schemes, such as the 0 verseas Doctors' Training Scheme, suggests that few doctors return to their home countries, and also points out that the IFP ignores the difficulties that doctors will face when they do return home. The IFP has not been running long enough yet to see whether or not this pattern will be repeated, though if it is then one would expect doctors recruited from poorer countries to be more likely to remain in the UK than those from wealthier ones.

Another point raised by Patel (2003) is that earlier schemes recruited junior doctors, but the IFP is taking highly experienced specialists. This will have an immediate effect on the human healthcare resources of developing countries and, Patel maintains, the IFP could perpetuate global health inequalities for generations.

0 ne group specifically identified as likely to be attracted by the prospect of living in the UK for a while but then return home at the end of their contracts, and from a country well supplied with doctors, are those from $\mathrm{N}$ orth America. U nlike candidates from low- and middle-income countries, there would not be an ethical concern about doctors from the USA and Canada being recruited, or remaining in the UK after their IFP contractual period. Unfortunately, at the time of writing, no $\mathrm{N}$ orth American psychiatrists have been recruited under this programme. The main reason is that most have undertaken only 4 years of postgraduate psychiatric training and therefore do not meet the requirements for specialist registration under Article 9 of the European Specialist Medical Q ualifications O rder 1995. This left as the main recruiting grounds Australia, N ew Zealand, South Africa and India. However, following pleas from $\mathrm{N}$ elson Mandela himself not to recruit in South Africa, the focus is now on the remaining three countries, and by far the greatest number of applicants at present is from India.

Having myself visited India to look into the operation of the IFP and, in particular, ways in which we might 'put something back', I found a paradoxical situation that makes the positions of both the UK Department of $H$ ealth and its critics correct to a certain extent. I understand, from the many psychiatrists to whom I spoke, that most mental health centres are understaffed and doctors are coping with enormous case-loads. This was clearly so in the centres that I visited. There are also many parts of the country - typically rural areas - that simply provide no mental healthcare at all. However, government spending on healthcare is a very small proportion of gross domestic product, and on mental health it is a very small proportion indeed of the overall healthcare budget. Consequently, on my visit the situation consistently reported to me by doctors is one where there is a serious shortage of doctors yet a lack of jobs, especially senior ones. The Indian government, however, seems to be saying something completely different: Jenkins (2004) states that 'the Indian Minister of Health and Family Welfare responded to a parliamentary question in July 2003 by saying that the overall availability of doctors in India is sufficient'.

Reporting on the situation in Pakistan, Khan (2004) is strongly critical of the IFP and, in particular, the undermining of mental healthcare there by the 'poaching' of psychiatrists. The N HS, he asserts, is 'bending all kinds of rules and cutting corners to lure overseas qualified psychiatrists to work in the N HS'. Turning his attention to the role of the College, Khan concludes that 'why the College consented to go along with the scheme is beyond comprehension' and continues with other robust criticisms.

However, Khan is misleading in some of his criticisms. For one thing, the IFP has never actively recruited in Pakistan. Information is available on the internet, of course, but it has never been targeted at Pakistan. In fact, very few Pakistani psychiatrists have been recruited under the IFP. The figures cited by Goldberg (2004) indicate that just 6 of the 124 psychiatrists recruited through the IFP were from Pakistan.

More serious, though, are Khan's criticisms that the College is complicit in 'bending ... rules' and 'is willing to validate an overseas psychiatrist's experience and qualifications without as much as a semblance of critical appraisal of the candidate's training programme and standard of examination in his/her home country'. The College has a trained team of staff dedicated exclusively to scrutinising applications from overseas psychiatrists. Those applying under the IFP and those who apply independently are all treated in exactly the same way. This involves checking and verifying their training and qualifications. Each case is considered individually and in detail, first by an experienced senior administrator and then by the Equivalence Committee, convened from a panel of consultant psychiatrists. Wherever possible, at least one committee member will be an expert in the 
specialist training and qualifications of the candidate's home country. The College recommendations are then sent to the Specialist Training Authority (STA) of the Medical Royal Colleges. Here the application is independently scrutinised, also by experts. The STA's recommendations are then passed to the General Medical Council for further scrutiny before they are finally accepted or rejected.

Far from 'making a mockery of the whole process of senior house officer training, approved higher specialist training [and] entry to the Specialist Register', as Khan accuses the College, we are meticulous in applying precisely the same high standards when processing IFP applications as we are with all other overseas applications for specialist registration. In fact, only a very small proportion of applications go through to specialist registration and almost all of the unsuccessful applications are sitted out by the very thorough College procedures. There is absolutely no question of the College colluding with the Department of $\mathrm{H}$ ealth or any other body in obtaining specialist registration for anyone lacking the required training, qualifications and experience. Even if such a candidate should somehow pass College scrutiny, there would still be two further checks, by the STA and the General Medical C ouncil, both, of course, independent of the Department of H ealth. H owever, it must be said that this rigour has been worthwhile because the quality of consultant psychiatrists recruited under the IFP has been very good.

Although Khan is mistaken about the standards of scrutiny observed by the College, he is absolutely correct in saying that in the past few years very considerable progress has been made both by the College of Physicians and Surgeons Pakistan and his own organisation, Aga Khan U niversity, in improving medical education and examinations. Indeed, I have served as an educational consultant myself to both these excellent organisations and have worked with them on several occasions, helping to develop curricula and examinations, and to train staff. As Mellor (2003) reports, much of the support from the UK to promote healthcare in developing countries receives little publicity. However, it is undoubtedly provided and I very much hope that such international collaboration will long continue.

\section{Some additional issues}

Although the current debate is predominantly about the rights and wrongs of international recruitment, there are two serious underlying questions that have received little or no airing to date. First, there must surely be grounds for discussion about the willingness of doctors to leave India and Pakistan. For example, there must be major ethical concerns that both countries spend so little on the health of their citizens, yet both have nuclear weapons. Patel (2003) also highlights the 'stifling hierarchies and bureaucracies' in some developing countries, citing as an example that in India promotion is more likely to be determined by length of service than by skills and achievements. So, it is possible that the IFP might not itself be the main reason for doctors leaving, but simply the vehicle that enables them to do so.

However, government incompetence, or at least a very strange sense of priorities, is not confined to India and Pakistan. 0 ur second underlying question might be 'W hy are there so many N HS consultant posts vacant? The UK government controls both the number of places available at medical schools and the national training numbers (NTN s) for specialist training, and both Labour and Conservative governments have been warned of the impending shortage of doctors for years. Yet, until comparatively recently, successive governments have done next to nothing about it. Even now, with an increase in the number of places allocated at medical schools, many feel that the steps being taken are quite inadequate and, in any case, it will be many years before any of today's medical students become consultants. Workforce policy seems to have been wrong for years - indeed, it has almost been a case of 'a policy of no policy'. Moreover, having exercised (or at least had) central control while the problem developed, it does seem a bit rich suddenly to use 'global market forces' as a justification for recruiting healthcare workers from poorer countries.

Perhaps we should all give more thought to how the world educates and makes the best use of its healthcare workers. If they are a global resource, which is what one justification for the IFP claims, then developed nations must do a great deal more giving, especially if they are also responsible for a lot of the taking. The need for the IFP at all is irrefutable evidence that we are not doing enough to educate and properly manage even our own healthcare workforce.

\section{References}

Goldberg, D. (2004) The N HS International Fellowship Scheme in Psychiatry. Reply to Khan. Psychiatric Bulletin, 28, 433434.

Jenkins, C. (2004) Ethical international recruitment. International Psychiatry, issue 6, 18-19.

Khan, M. M. (2004) The N HS International Fellowship Scheme in Psychiatry: robbing the poor to pay the rich? Psychiatric Bulletin, 28, 435-437.

Mellor, D. (2003) Commentary. Recruitment is ethical. British Medical Journal, 327, 928.

$\mathrm{N}$ detei, D., Karim, S. \& Mubbashar, M. (2004) Recruitment of consultant psychiatrists from low- and middle-income countries. International Psychiatry, issue 6, 15-18.

Patel, V. (2003) Recruiting doctors from poor countries: the great brain robbery? British Medical Journal, 327, 926-928.
So, it is possible that the IFP might

not itself be the main reason for doctors leaving,

but simply the vehicle that

enables them to do so.

Workforce policy seems to have

been wrong for years - indeed, it has almost been a case of 'a policy of no policy'.

Moreover, having exercised (or at least had) central control while the problem developed, it does seem a bit rich suddenly to use 'global market forces' as a justification for recruiting health care workers from poorer countries. 